\title{
Simulation of Combustion Air Flow in the Gasification Biomass Boiler
}

\author{
Marek Patsch ${ }^{1, *}$, and Peter Pilát ${ }^{1}$ \\ ${ }^{1}$ University of Žilina, Department of Power Engineering, Univerzitná 1, 01026 Žilina, Slovakia
}

\begin{abstract}
The article deals with the optimization of biomass combustion in a small heat source by means of an optimal distribution of combustion air. The uneven distribution of combustion air has been observed in certification tests and in real operation of used heat source and it has an influence on uneven combustion of biomass in the gasification chamber, on increase emissions and combustion losses. At this stage of the research, optimization of the combustion air distribution is performed by CFD simulations, which will be later verified by PIV measuring of the velocity fields in gasification and combustion chambers of the experimental heat source. CFD simulations and subsequent PIV measurements on the experimental device are realized without real combustion, only the air flow in the empty gasification chamber and in the combustion chamber is investigated. This approach has been chosen to simplify calculations and experiments, and on the assumption that when the combustion air distribution is optimal in empty chambers, it will be optimal even during real combustion. The primary air flow in the gasification chamber is in real operation affected by the size and shape of the inserted biomass and its placement in chamber and this effect is accidental and difficult to verifiable.
\end{abstract}

\section{Introduction}

Gasification heat sources are a modern way of biomass energy utilization where combustion is with high efficiency and low emissions [6]. The combustion takes place in a three-stage process and it can be divided into three zones. In the first zone there is drying and gasification of the wood with access of the primary combustion air, volatile substances are released from the solid fuel. Gasification is, in principle, the thermal decomposition of organic and inorganic substances in the closed chamber of the boiler under a slight overpressure produced by the combustion air fan. This gasification process is carried out in the fuel container, above the refractory nozzle. In the second zone, released gases with preheated secondary air are mixed in the nozzle space to form a mixture of combustion gas. In the third zone there is a total burning of gases in the boiler's combustion chamber and the removal of flue gases through the pipe heat exchanger into the chimney. In this controlled combustion process a high efficiency is guaranteed - 80-90\%, the boiler's heat output is continuously adjustable in the range of $40-100 \%$ of nominal power [1].

\footnotetext{
*Corresponding author: marek.patsch@fstroj.uniza.sk
} 
CFD simulations and subsequent measurements on the experimental heat source were made on a model based on biomass gasification boiler Vigas 16 (Figure 1). Operation of this heat source in laboratory conditions showed uneven distribution of combustion air, resulting in residual unburned fuel remaining, increased emissions and reduced nominal heat power.

Important factors affecting emission and ash generation are the distribution of combustion air to primary and secondary, its distribution to the air inlets (the heat source has four primary and six secondary air inlets) and the velocity of combustion air [3-5]. Optimal flow of primary combustion air in the gasification chamber and secondary combustion air in the nozzle at the inlet to the combustion chamber has a major impact on the process of gasification and subsequent combustion of biomass. The amount of supplied combustion air is given by the fan speed, the portion of the total amount of air being taken away as secondary air, and the rest is the primary combustion air. The amount of secondary air is determined by the setting of the secondary air valve.

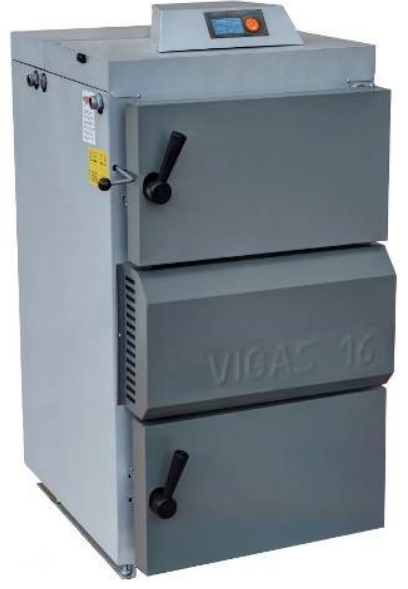

a)

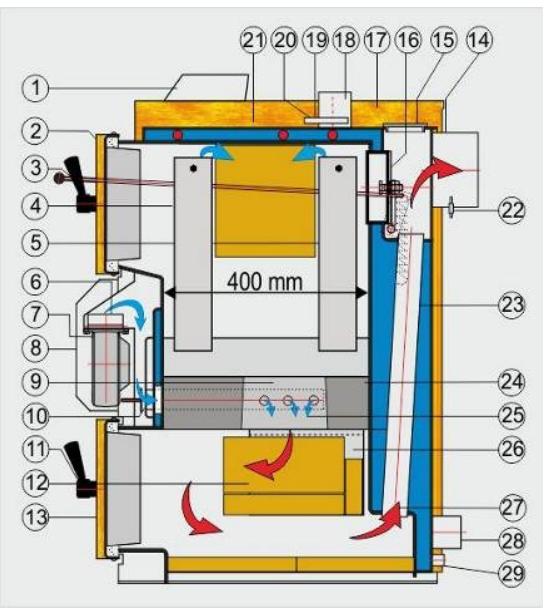

b)

Fig. 1. a) Gasification boiler Vigas 16 [2], b) section of the gasification boiler: 1. regulation, 2. upper door, 3. chimney flap rod, 4. gasification chamber, 5. primary air line, 6. damper actuator, 7. combustion air fan, 8. fan cover, 9. refractory concrete block, 10. secondary air valve, 11. door closure, 12. refractory hearth lining, 13. lower door, 14. chimney, 15. exchanger cover, 16. firing flap, 17. top back cover, 18. water outlet, 19. thermal fuse, 20. boiler thermometer, 21 front cover, 22. Flue gas thermometer, 23. pipe heat exchanger, 24. primary air chamber, 25. secondary air, 26. combustion chamber, 27. direction of the flue gas, 28. water return, 29. filling water throat [2].

\section{Numerical design for CFD simulations}

The 3D model (Figure 2) was constructed according to the design documentation, followed by the generation of a calculation mesh with approximately 1400000 elements. The calculation was performed in Fluent, the standard $k-\varepsilon$ model and the standard wall functions were used. Simulated was only the combustion air flow without combustion, used were a constant air temperature of $288.16 \mathrm{~K}$, a constant density of $1.225 \mathrm{~kg} \cdot \mathrm{m}^{-3}$ and a viscosity of $1.7894 .10^{-5}$ Pa.s, considered with a turbulent flow.

In the evaluation, all computational volume was divided into twelve sections, and for each section the flow rate was evaluated at fifteen combustion air fan settings, corresponding to a volume flow rate of 10 to $150 \mathrm{~m}^{3} \cdot \mathrm{h}^{-1}$. 


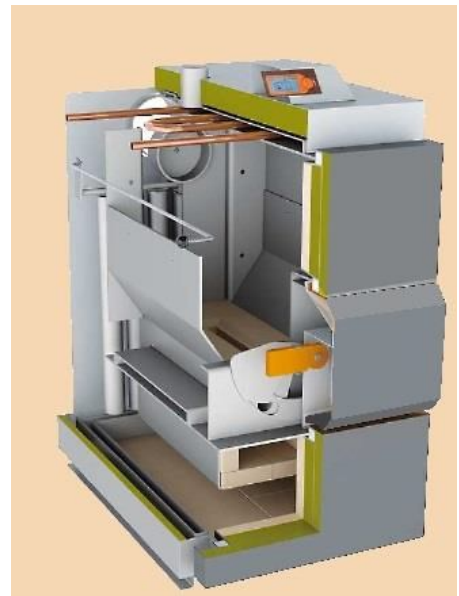

a)

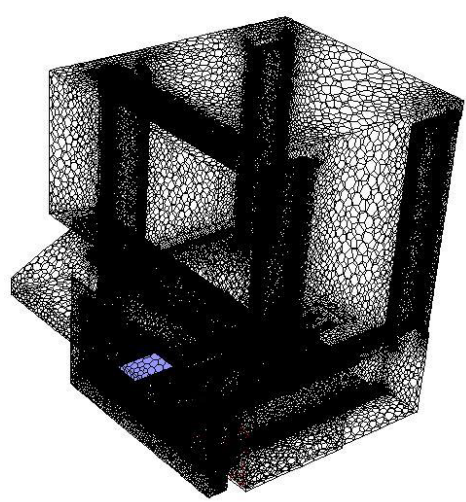

b)

Fig. 2. a) 3D model of gasification boiler Vigas 16 , b) Calculation mesh for CFD analysis.

\section{Evaluation of CFD simulations}

Figure 3 shows an example of calculated flow in the gasification and combustion chamber in a vertical cross-section which is guided by the axis of the heat source. Simulations have shown in particular the uneven distribution of primary air flow in the gasification chamber at higher volumetric air flow through the combustion air fan. This is result of higher pressure and length losses from air fan to primary air inlets. All inlets have the same crosssectional area, so the optimization step should be to change the cross-sectional area (distant air inlets have to have higher cross-section area to reduce pressure losses, or closer air inlets have to have smaller cross-section area to increase pressure losses). The distribution of secondary air appears to be uniform in this cross-section $[7,9]$.

The more uneven distribution of primary air is more apparent in vertical cross-sections which are guided closer to the wall of the gasification chamber. Figure 4 shows strong effect of air flow reflection from the bottom of the empty gasification chamber. This effect would not be so pronounced in the wood-filled chamber.

Figure 5 shows an example of a flow distribution and velocities in a gasification chamber in a horizontal cross section which is guided approximately in half the height of the gasification chamber. At higher volumetric flows through the fan, the highest velocity of the primary combustion air is achieved at the right front inlet. It results from the location of the combustion air fan which is located on right side of heat source axis, i.e. closest to that air inlet. Also, the air flow to the inlet is larger on the right side, closer to the fan, which causes less pressure and length losses on this side. As already mentioned all primary air inlets have the same cross-sectional area, so there are two ways to the optimization. The first option is to change the cross-sectional area of the distant or closer inlets, the second option is to change the position of combustion air fan into the vertical axis of the heat source $[10,11]$.

Figure 6 shows an example of a flow distribution in the gasification and combustion chamber in a vertical cross-section which is guided through the second pair of secondary air inlets (perpendicular to the longitudinal axis of the heat source), viewed from the rear side of the heat source. At higher volumes of combustion air through the fan there is an apparent uneven distribution of primary air in the gasification chamber, the flow being diverted from the chamber axis, which is caused by a larger flow rate of primary air through the right 
inlets closer to the fan. It is also possible to observe a slight diversion of the secondary air flow in the nozzle into the combustion chamber. The maximum nozzle speed is $6 \mathrm{~m} \cdot \mathrm{s}^{-1}$.
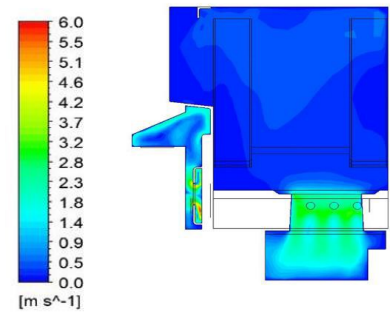

$40 \mathrm{~m}^{3} \cdot \mathrm{h}^{-1}$

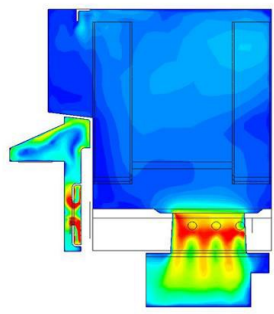

$80 \mathrm{~m}^{3} \cdot \mathrm{h}^{-1}$

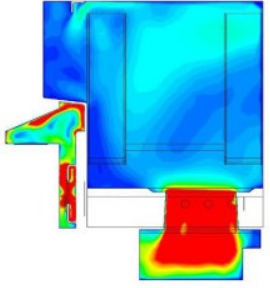

$90 \mathrm{~m}^{3} \cdot \mathrm{h}^{-1}$

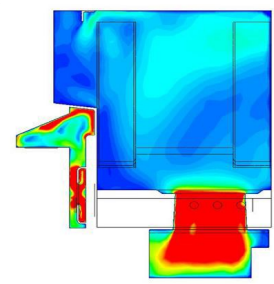

$150 \mathrm{~m}^{3} \cdot \mathrm{h}^{-1}$

Fig. 3. Example of calculated velocity fields in gasification and combustion chamber in different volumetric air flows (vertical cross-section in device axis).

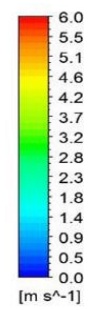

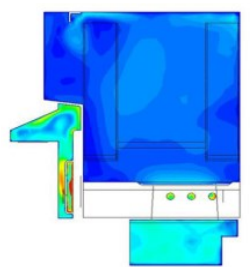

$80 \mathrm{~m}^{3} \cdot \mathrm{h}^{-1}$

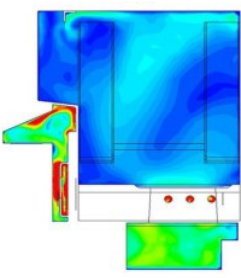

$100 \mathrm{~m}^{3} \cdot \mathrm{h}^{-1}$

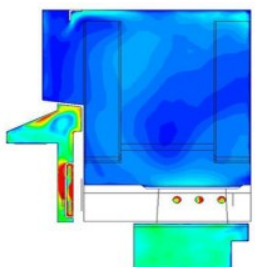

$110 \mathrm{~m}^{3} \cdot \mathrm{h}^{-1}$

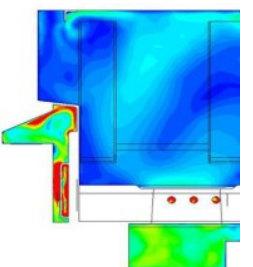

$150 \mathrm{~m}^{3} \cdot \mathrm{h}^{-1}$

Fig. 4. Example of calculated velocity fields in gasification and combustion chamber in different volumetric air flows (vertical cross-section closer to wall of gasification chamber).
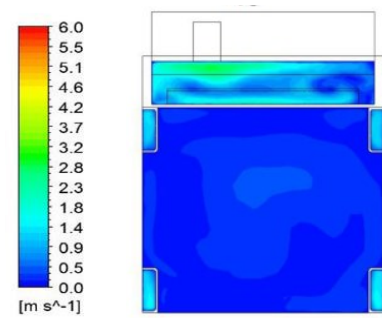

$40 \mathrm{~m}^{3} \cdot \mathrm{h}^{-1}$

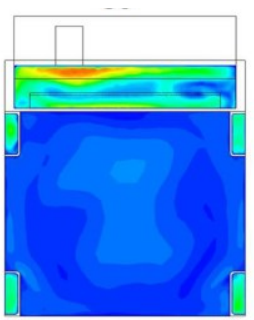

$80 \mathrm{~m}^{3} \cdot \mathrm{h}^{-1}$

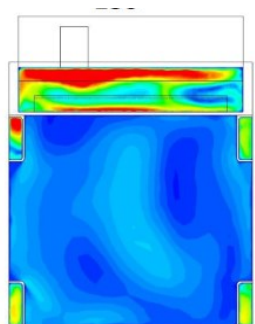

$130 \mathrm{~m}^{3} \cdot \mathrm{h}^{-1}$

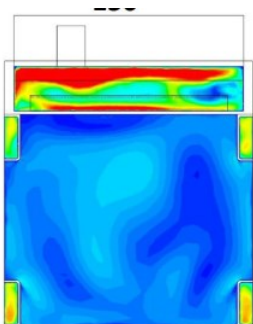

$150 \mathrm{~m}^{3} \cdot \mathrm{h}^{-1}$

Fig. 5. Example of calculated velocity fields in gasification chamber in different volumetric air flows (horizontal cross-section in half the height of gasification chamber).

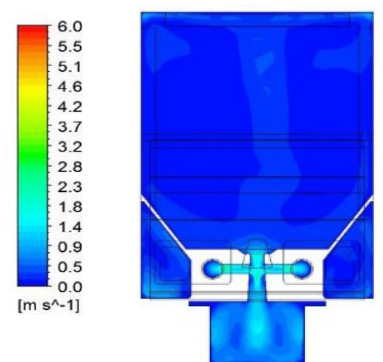

$30 \mathrm{~m}^{3} \cdot \mathrm{h}^{-1}$

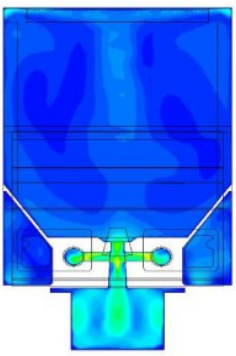

$60 \mathrm{~m}^{3} \cdot \mathrm{h}^{-1}$

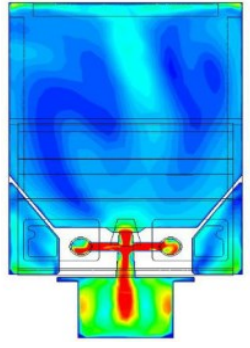

$90 \mathrm{~m}^{3} \cdot \mathrm{h}^{-1}$

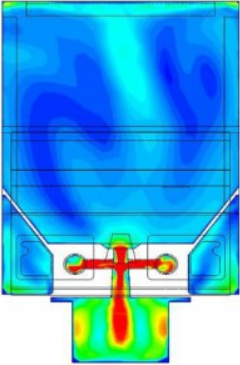

$150 \mathrm{~m}^{3} \cdot \mathrm{h}^{-1}$

Fig. 6. Example of calculated velocity fields in gasification and combustion chamber in different volumetric air flows (vertical cross-section through the secondary combustion air inlets, viewed from the rear side). 
The uneven distribution of primary air in the gasification chamber is also apparent from the graph on Figure 7, which shows the percentage distribution of air at the inlets of the right and left pairs of primary air inlets. Through the right side, which is closer to the fan, at higher volumetric air flows through the combustion air fan more than $5 \%$ primary combustion air flows.

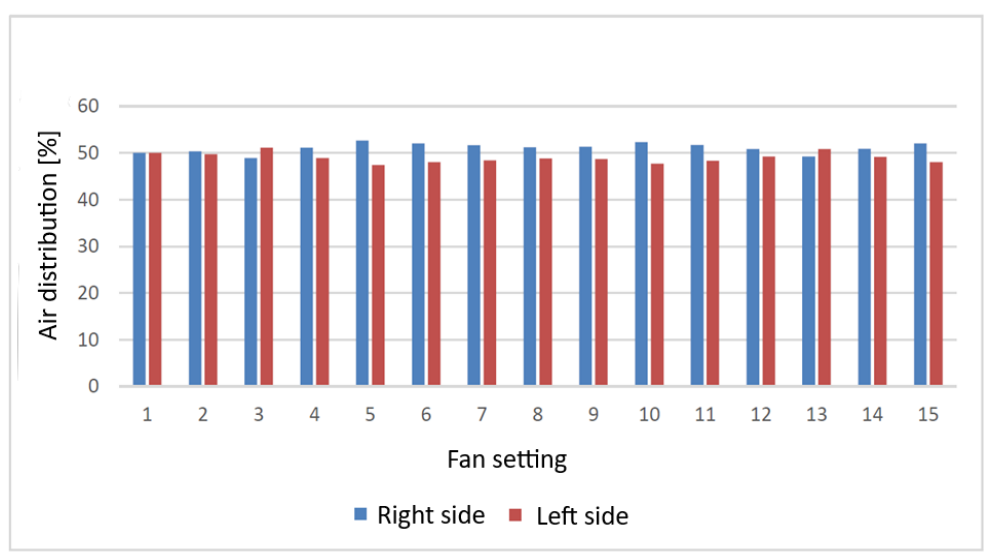

Fig. 7. Percentage distribution of primary air at right side and left side inlets (fan setting scale: 1 means $10 \mathrm{~m}^{3} \cdot \mathrm{h}^{-1}$ to 15 means $\left.150 \mathrm{~m}^{3} \cdot \mathrm{h}^{-1}\right)$.

\section{Conclusion}

Modelling and CFD simulations confirmed the uneven distribution of primary air in the gasification chamber and partly confirmed the uneven distribution of secondary air in the combustion chamber nozzle, which were also observed in the real operation of a small heat source. The uneven distribution of secondary air needs to be dealt with in more detail later and, in particular, to compress the computing mesh at a given location because it is a small space compared to the overall computing volume. The computational CFD model will be verified and optimized by PIV velocity fields measurements on the real gasification biomass boiler model. Flow optimization will be achieved by moving the combustion air fan and changing the cross sectional areas of the primary and secondary air inlets.

This article was realised in the frames of project VEGA 1/0864/16 "Analysis and optimization of input factors in the process of dendromass combustion in small heat sources".

This article was created with grant KEGA 042ŽU-4/2016 „Cooling on the basis of physical and chemical processes“.

This publication is the result of the Project implementation: Competency Centre for Knowledge technologies applied in Innovation of Production Systems in Industry and Services, ITMS: 26220220155, supported by the Research \& Development Operational Programme funded by the ERDF.
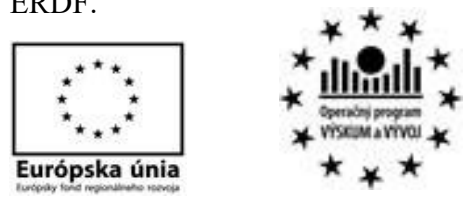


\section{References}

1. J. Jandačka, M. Malcho, M. Mikulík, Technológie pre prípravu a energetické využitie biomasy (2007)

2. Technical documentation of gasification biomass boiler Vigas 16 (2016)

3. T. Nussbaumer, M. Kiener, 21st European Biomass Conference (2013)

4. M. Kiener, T. Nussbaumer, 20th European Biomass Conference (2012)

5. T. Nussbaumer, M. Keiner, P. Horat, Biomass and Bioenergy, 76 (May 2015)

6. S. Van Loo, J. Koppejan, The Handbook of Biomass Combustion and Co-firing (Earthscan, London, 2008)

7. K. Sulovcová, R. Nosek, J. Jandačka, M. Holubčík, Emis. Cont. Sc. and Tech. (2018)

8. M. Holubčík, J. Jandačka, R. Nosek, J. Baranski, Emis. Cont. Sc. and Tech. (2018)

9. N. Kantová, J. Jandačka, M. Holubčík, A. Čaja, 36th Meeting of Departments of Fluid Mechanics and Thermodynamics (2017)

10. P. Oršanský, B. Ftorek, P. Durčanský, AEaNMiFMaE 2014 (2014)

11. Š. Papučík, R. Lenhard, et al., AIP Conference Proceedings 1608 (2014) 